\title{
AC 2007-1069: DEVELOPING AN ENERGY LITERACY SCALE
}

\section{Jan DeWaters, Clarkson University}

Jan DeWaters, PE is currently pursuing a PhD degree in Environmental Science and Engineering at Clarkson University, with a focus on energy and environmental education. She has several years of experience as the curriculum coordinator for Clarkson's Project-Based Learning Partnership Program and is director of the Partners in Engineering Program that provides mentoring and engineering activities for eighth grade girls.

\section{Susan Powers, Clarkson University}

Susan E. Powers, PhD, PE is a Professor of Civil and Environmental Engineering and Associate Dean in Engineering for Research and Graduate studies at Clarkson University. She has directed an NSF-Funded GK-12 Program - Project-Based Learning Partnership Program since 1999 and received the NSF Directors Award for Distinguished Teaching Scholars in 2004.

\section{Mary Graham, Clarkson University}

Mary Graham, $\mathrm{PhD}$ is an Associate Professor in Organizational Studies at Clarkson University. Her research interests include gender-related employment discrimination. 


\section{Developing an Energy Literacy Scale}

Energy is the "underlying currency that governs everything humans do with each other and with the natural environment that supports them." " Our reliance on energy-rich sources of fossil fuels has created the underpinnings of modern society, enabling mobility, industrial growth, domestic comfort, unprecedented lavish food supply, and economic prosperity. Inarguably, energy is one of the most important issues of the $21^{\text {st }}$ century. As we move into a future with limited fossil fuel resources and worsening environmental conditions, our society is faced with defining new directions with respect to energy consumption, resources, and independence. An informed, energy-literate public is more likely to be engaged in the decision making process, and will be better equipped to make thoughtful, responsible energy-related decisions, choices, and actions.

A number of surveys have been conducted over the years to assess energy-related knowledge and awareness among American school students and the general public, ${ }^{2-9}$ and the results have been largely mixed. While a few encouraging consumer studies suggest a moderate degree of knowledge among consumers about specific topics such as energy use and local implementation

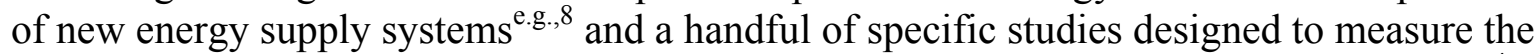
impact of energy-related curricula on student knowledge have shown positive results, ${ }^{\text {e.g., }}{ }^{4}$ by far the majority of data indicate a lack of general energy-related knowledge and awareness. ${ }^{3,6,7,10,11}$ For example, the National Environmental Education \& Training Foundation (NEETF) found in a 2001 survey that, while many Americans tended to overestimate their energy knowledge, just $12 \%$ could pass a basic quiz on energy knowledge. ${ }^{6}$ More recent findings from a general questionnaire on climate change and the environment developed at the Massachusetts Institute of Technology (MIT) revealed that most respondents had not heard or read about hydrogen cars, wind energy, or nuclear energy. In fact, $17 \%$ of the people surveyed had not heard of any of the listed items. ${ }^{7}$

One of the most limiting factors of studies that purportedly measure energy-related knowledge and awareness is the choice and range of actual questions posed to the respondents. The outcome of efforts that are more narrowly focused on specific curricular topics or consumeroriented issues is bound to differ from a study that takes a broader or more superficial tact, which makes comparing these types of studies difficult if not impossible. A more narrowly focused survey instrument is clearly limited in its ability to measure "general" energy-related knowledge and awareness; yet the outcome of a broader instrument that covers a wider range is still limited by the choice of questions posed. What, then, is the appropriate choice and range of survey questions, if the desired outcome is a measure of energy literacy?

The goal of this paper is to explore this issue in depth. This investigation lays the framework for a research project whose intent is to develop a written survey that adequately assesses energy literacy among middle and high school students. A sampling of background information provides the basis for defining energy literacy and identifying appropriate assessment methodologies. The remainder of the paper details the methodology and results of the first major step in developing the survey tool - establishing a set of criteria against which energy literacy can be measured. 


\section{Background}

\section{A Basis for Defining Energy Literacy}

Culturally literate people in every society and every culture share a body of knowledge that enables them to communicate with each other and make sense of the world around them. The kinds of things a literate person knows will vary from society to society and

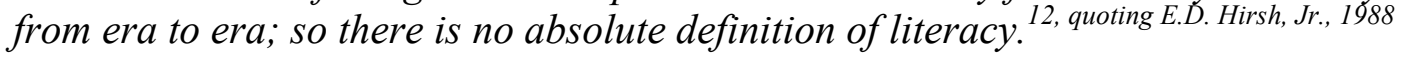

Hirsh's fluid definition of cultural literacy contends that, even in its barest sense, literacy cannot be sufficiently defined by the possession of a limited set of factual knowledge. Given the limitations of knowledge, per se, literacy becomes not only a way of knowing, but also a way of being - curious, objective, and capable of assessing and applying information and skills to make sound decisions and actions. Literacy implies not only the understanding of a particular, relevant body of knowledge and set of relationships, but moreover, the ability and willingness to use that knowledge in a functional manner - to read and write, to communicate, to participate in society.

Efforts to define energy literacy can be modeled after work that has been done in the fields of both technology and environmental science, where the scope of literacy includes, but extends well beyond, conceptual knowledge. Standards for technology education developed by The International Technology Education Association and the International Association for Technology in Education stipulate that technological literacy is the ability to use, manage, analyze, assess, and understand technological systems for solving problems, communicating, and participating in society. ${ }^{13,14}$ Following along the lines of these educational-based criteria for technological literacy, yet using a more systematic approach, the National Academy of Engineering (NAE) and the National Research Council (NRC) defined technological literacy broadly as encompassing three dimensions: knowledge; ways of thinking and acting (critically analyzing, assessing); and capabilities. ${ }^{12}$

Since as early as the 1970's, environmental science educators and education professionals have also emphasized the application of skills and knowledge in attempting to set criteria for environmental literacy. Environmental literacy lacks a clear definition, but the Tbilisi Declaration of $1977^{15}$ was modified in $1990^{16}$ to state: "Environmental literacy is a basic functional education for all people, which provides them with the elementary knowledge, skills, and motives to cope with environmental needs and contribute to sustainable development." Defined essentially in terms of observable behaviors, environmental literacy empowers individuals with knowledge, attitudes, motivations, commitments, and skills to work individually and collectively toward the solution of current problems and the prevention of new ones. ${ }^{17-19}$ Thus we see the emergence of three dimensions, similar to those defined by the NAE and NRC for technological literacy: knowledge; skills (similar to technological literacy's "capabilities"); and motivations, personal investment, responsibility, and active involvement, or "habits of mind" (similar to technological literacy's "ways of thinking and acting"). ${ }^{18,19}$ An operational definition of environmental literacy developed by Roth slightly re-aligns these three dimensions into four strands: knowledge, skill, affect, and behavior. ${ }^{18}$ Figure 1 graphically demonstrates how these definitions of literacy encompass the cognitive domain (conceptual knowledge or understanding, skills), the affective domain (sensitivity/attitude, personal responsibility), and behavior attributes (active involvement). 


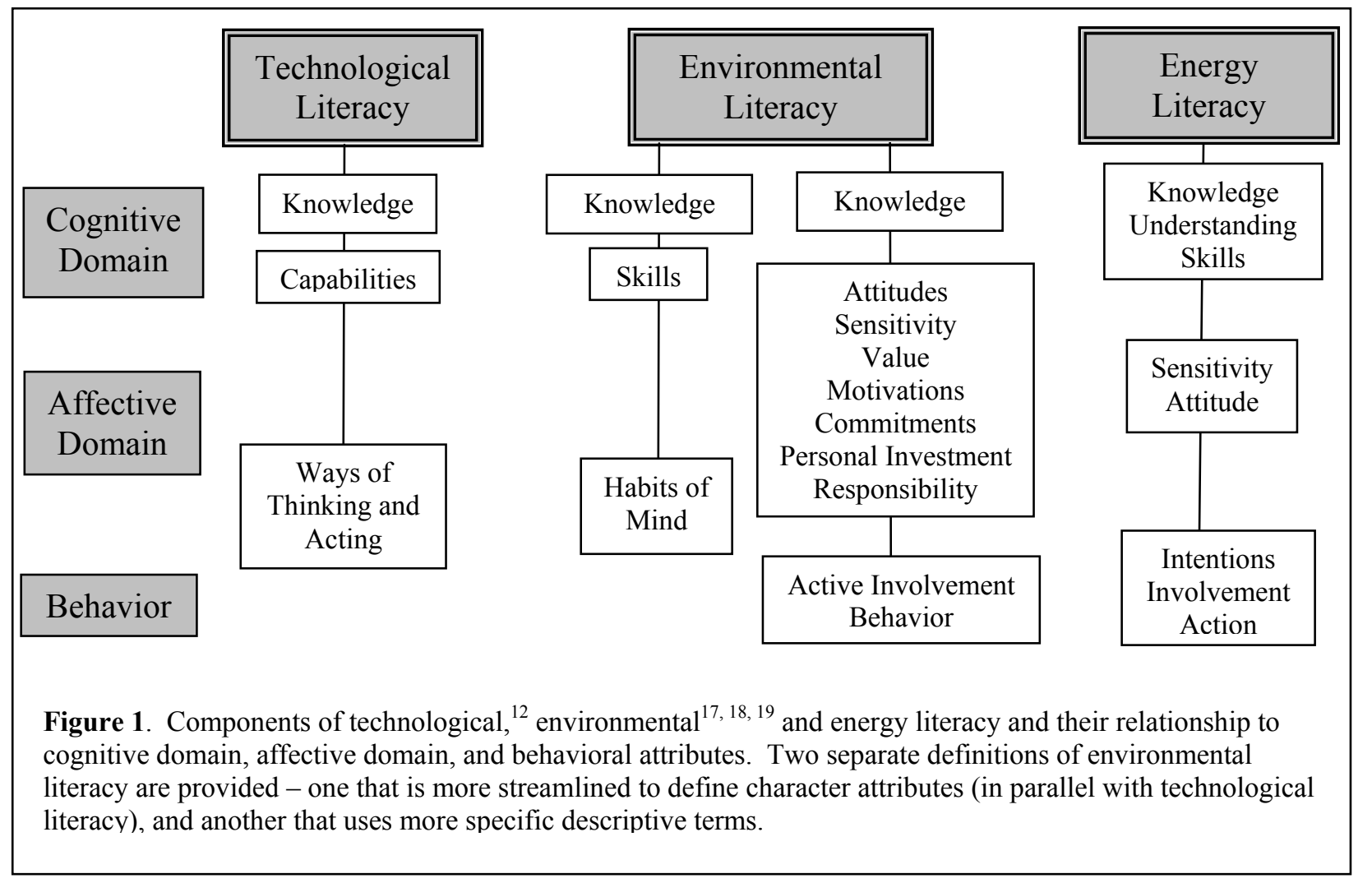

Efforts to define technological and environmental literacy form the basis for our work in defining energy literacy - described here as encompassing knowledge, understanding, and skills; sensitivity/attitudes; and - ultimately - intentions, involvement, and action (Figure 1). Similar to technological and environmental literacy, our definition of energy literacy encompasses both cognitive and affective domains, and is broadly categorized into the three dimensions of knowledge, sensitivity/attitudes, and intentions/behaviors. Specifically, an energy literate individual is one who:

- has a basic understanding of how energy is used in everyday life;

- has an understanding of the impact that energy production and consumption have on all spheres of our environment and society;

- is sensitive to the need for energy conservation and the need to develop alternatives to fossil fuel-based energy resources;

- is cognizant of the impact of personal energy-related decisions and actions on the global community; and

- strives to make choices and decisions that reflect these attitudes with respect to energy resource development and energy consumption.

Defining energy literacy in terms of knowledge, attitudes, and behaviors in this way leaves open important questions for discussion: how much, and what kinds, of knowledge are important for energy literacy? What types of behaviors and attitudes typify an energy literate individual? This second question is somewhat easier to answer, particularly given the breadth of environmental education literature on a similar topic. ${ }^{\text {e.g.,20-22 }}$ Attitudes and behaviors appropriate for energy literacy may generally be considered as those consistent with acknowledging the existence of 
global energy problems and exhibiting a willingness to take part in their solution. The question concerning the importance of knowledge is more difficult, and has been addressed by various educators over the last few decades. ${ }^{19,23,24}$ Clearly, the goal is to empower people with the knowledge, skills, and attitudes needed to make informed choices, rather than to dictate a required set of factual information or advocate a particular line of thinking. It is also clear from behavior and education research that determinants of (environmental/energy-responsible) behavior include a complex interaction between cognitive understanding, skill, and affective attributes such as values, attitudes, and sensitivity. ${ }^{\text {e.g.,25 }}$ Nevertheless, the question remains: how much, and what types of knowledge and understanding are critical for empowerment?

An energy literate person needs to have a basic understanding of energy concepts. A sound knowledge base is important; gains in knowledge will generally improve a person's selfconfidence in that area, and as a person gains confidence in their ability to ask intelligent questions and think critically about a subject, they are more likely to become active and to participate in decision-making. ${ }^{12}$ The major role that awareness and cognition play in determining literacy is not in question; of concern are the depth of knowledge, and the relative importance of different types of energy-related concepts. On the one hand, energy content knowledge can refer to general energy and environmental issues on a local and global scale, comprehension that lies at the intersection with consumer actions and decisions (e.g., product ratings of energy consumption; electric power supply; automobile fuel mileage). At the other extreme are scientific concepts related to energy. Certainly, an energy literate person needs to have a basic comprehension of fundamental scientific principles so they can understand the consequences of energy development and use on human and natural systems. But what depth of scientific understanding is necessary to ensure "literacy?"

Helenmarie Hofman contrasts "practical" with "technical" energy knowledge, and argues that an energy literate person needs to understand and be able to apply "cultural concepts and practices. ${ }^{23}$ In Getting to Know about Energy - in School and Society, ${ }^{24}$ Joan Solomon refers to a "citizen understanding of energy" and asks: what kind of knowledge about energy does a citizen need, and for what purposes? Given the prominent role that energy issues play in today's world, it follows that people need to have a basic understanding of energy concepts but also need to be able to critically analyze and decipher information in order to effectively make choices and decisions. She uses the term "informal knowledge" to refer to energy knowledge that is important to a citizen making their way in society, but not necessarily sufficient for an energy scientist or professional. For example, in describing energy education for society's citizen, Solomon brings up four topics including power generation, oil/fuel shortages, alternative energy resources, and global perspectives. Citizens need to understand that fossil fuel reserves are running out, that there are alternative resources available yet these are still undeveloped or inefficient, and that electricity must be generated from an energy source. "Formal" knowledge associated with these ideas might include, for example, the processes used to derive heat from fossil fuels, information that is typically more in line with what students learn about energy in traditional science programs but may not necessarily help a citizen to function in society.

The focus of energy literacy should remain on critical thought, ultimately resulting in the outcome of learner empowerment and action as the final measure of effectiveness. An overemphasis on scientific content knowledge will tend to water down this focus. According to St. Clair, an emphasis on "scientific knowledge" narrows the lens through which we view energy 
and environmental literacy, and "enshrines Western science as the primary means for humans to engage with the environment." Additionally, assuming that literacy requires a high level of scientific training has the potential to create an "elite of [environmentally] literate citizens and a mass of people who either follow along or are completely excluded from informed environmental action." 21

\section{Efforts to measure energy literacy}

Efforts to assess energy-related knowledge and attitudes include classroom application as well as consumer-oriented studies. Except for a few general studies, ${ }^{\text {e.g.,3, }}{ }^{10}$ assessment directed toward middle and high school students has most commonly been in the form of a written test or survey following student participation in an energy curriculum. This type of assessment is typically limited to conceptual knowledge, somewhat narrowly focused on specific curricular objectives. e.g.,4, 26, 27 Alternatively, energy surveys have been administered to more broadly assess energy-related knowledge and attitudes among consumers, ${ }^{\text {e.g., }}{ }^{6-8}$ yet while many of these are more general in scope, some are designed for telephone administration, and others are too lengthy and mature for practical classroom application.

\section{Use of Questionnaires}

Formal evaluation is most efficiently carried out with a written closed-item questionnaire, although the limits of a closed-item questionnaire warrant the use of additional types of measures for adequate triangulation. One of the most common inadequacies of a closed-item questionnaire, particularly when attempting to measure less tangible, affective constructs, is the failure to comply with rigorous procedures to ensure instrument validity (determining that the instrument measures the intended objective or construct) and reliability (determining that the instrument produces consistent results). Adequately defining measurement objectives or criteria within the construct under investigation (in this case, energy literacy) precludes the ability to create a valid and reliable scale that quantifies measured outcomes. Defining energy literacy in terms of cognitive and affective domain and behavioral aspects simplifies this process somewhat. Cognitive measurement objectives related to knowledge and understanding are relatively simple to measure with written assessment techniques; affective and behavioral measurement objectives are more difficult to quantify with closed-item questionnaires, since these cannot be measured directly but must be inferred through self-report using a graduated-intensity response scale such

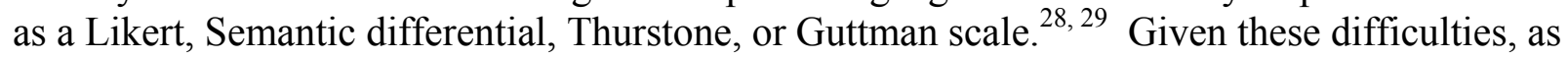
well as the complex relationship between self-reported attitudes and behavior, firmly establishing instrument reliability and validity are particularly important.

\section{Research Objectives}

The overall objective of this research is to develop a valid and reliable measure of energy literacy, that meets the following criteria: 1) is appropriate for students at the middle and high school level, in terms of language, level of conceptual understanding, and appropriateness of topics; 2) is convenient for use in a classroom setting; 3) can be completed within a 30-minute period; 4) is easily scored; and 5) is comprehensive in nature, closely correlated to critical benchmarks that define energy literacy in terms of students' energy-related knowledge, attitudes, and intentions/behaviors. 
The foundation for developing the energy literacy scale rests on firmly establishing a set of criteria by which to measure energy literacy. The research presented in this paper will focus on the methodology and results associated with this first major step - establishing characteristics and criteria for energy literacy. These criteria form the basis for developing a framework, from which the energy literacy scale can be developed.

\section{Framework and Instrument Development Methodology - The Big Picture}

Methods for developing the Energy Literacy Survey are based largely on earlier work done by the Wisconsin Center for Environmental Education and the Wisconsin Environmental Education

Board as part of the Wisconsin Environmental Literacy Assessment Project, ${ }^{30,31}$ and were guided in part by studies to define characteristics and measurable benchmarks in environmental literacy ${ }^{19}$ and technological literacy. ${ }^{12}$

Survey development is a stepwise endeavor that relies on the efforts of the primary researchers, an ad hoc panel of energy and education experts, and a host of volunteer educators and students. The basic steps for creating the instrument include: initially defining the objectives/criteria to be measured (ultimately resulting in an "instrument development framework", which is an outline of specific energy literacy criteria); reviewing related surveys, quizzes and test to develop a pool of potential survey questions that match the defined objectives; preparing, administering and evaluating a pilot instrument; and finally, evaluating the pilot and revising the final survey instrument. (adapted from 30) Instrument validity is established through a variety of measures: by applying the construct definition (e.g., definition of energy literacy) and reviewing/applying prior energy education and knowledge/attitude/behavior research; by using items drawn from existing energy and environment surveys; and through a survey review process involving a panel of experts in energy and energy education (the "validity panel").

\section{Role of the Expert Validity Panel}

The assistance of an ad hoc panel of energy-experts, educators, and energy-education specialists has been essential for creating the instrument development framework and pilot instrument. The six-member panel includes a middle school science teacher, two energy education specialists, the executive director of an energy efficiency advocacy and technical services non-profit organization, a professor from St. Lawrence University's Department of Environmental Studies who teaches courses on energy and energy issues, and a mechanical engineering professor from Clarkson University whose research focuses on wind energy and energy efficiency. This diversity of backgrounds provides a range of perspectives for evaluating the criteria against which energy literacy is measured (thereby providing construct validity), and is instrumental for designing the survey to include appropriate questions to meet these criteria (thereby providing content and face validity).

Using methods drawn from the work of Peri and Quale, in developing environmental literacy surveys, ${ }^{30,31}$ and Kane, in developing a conceptual framework for a renewable energy curriculum, ${ }^{32}$ the validity panel reviewed initial drafts of the objectives and criteria for energy literacy and ultimately approved an Instrument Development Framework, as described below, to establish construct validation. The review process was carried out through independent review followed by the sharing of ideas and discussion to facilitate consensus among the group. In a 
similar fashion, the validity panel will review and approve the final set of survey items for use in the pilot instrument, helping to establish content and face validity of the instrument.

\section{Characteristics and Criteria for Energy Literacy}

Establishing a set of measurable criteria for energy literacy follows directly from the groundwork laid as we developed our comprehensive definition of energy literacy, described above. Like the definition, the set of criteria broadly encompasses the three dimensions of content knowledge, sensitivity and attitude, and intentions/behaviors, allowing the resulting survey instrument to be categorized into three convenient subscales. Specific characteristics described in our definition give rise to specific criteria or objectives within each dimension, enabling us to quantify our measure of energy literacy in terms of cognitive, affective, and behavioral attributes.

\section{Methodology}

The development process begins with defining the characteristics of energy literacy. Literacy characteristics include general statements of what people know and understand, the skills they share that enable them to use that knowledge and understanding, and their "habits of mind" 19 or "ways of thinking and acting." 12 In keeping with this general idea, but to be consistent with our definition of literacy within the cognitive and affective domains and behavior attributes, the categories have been realigned to the themes of "knowledge, attitude, and behavior/intention."

Based on our previously developed definition of energy literacy, and with input from a thorough review of educational literature, curricular materials, and state and national education standards, ${ }^{\text {e.g., }}$ 19, 23, 33-35 an energy literate individual has the following characteristics:

* Has a sound knowledge and understanding of energy issues, including:

- Basic scientific energy facts

- Issues related to energy sources and resources

- The importance of energy use for individual and societal functioning

- General trends in U.S. and global energy resource supply and use

- The impact energy resource development and use can have on people, society, and the environment

- The impact individual and societal decisions related to energy resource development and use can have on the ability of societies to effectively satisfy future energy needs

Share common attitudes, which include:

- Sensitivity to/awareness of the complexity and urgency of the global energy situation

- Positive attitudes and values regarding personal, societal, economic, and environmental impacts associated with energy resource development and use

- Strong efficacy beliefs

* Share some common energy-related intentions and behaviors, in that s/he:

- Works to conserve energy

- Makes thoughtful effective energy-related decisions

- Is an advocate for change 
Each of these characteristics refers to a set of specific concepts or, in the case of intentions and behaviors, a set of opportunities for demonstrating the characteristic. For example, "Issues related to energy sources and resources" includes the following concepts (excerpted from a list of nine concepts in all):

o The principal source of energy on earth is the sun.

o Energy resources are described as renewable and nonrenewable.

o There are advantages and disadvantages to using different energy resources, in terms of technical, environmental, economic, and societal concerns.

While demonstrable behaviors related to "Makes thoughtful effective energy-related decisions" include:

o Assesses objective, reliable information relevant to energy issues

o Evaluates pros and cons related to energy consumption from various renewable and nonrenewable resources

o Remains open to new ideas

o Evaluates costs and benefits related to energy when making consumer purchases

Validity panel members reviewed these characteristics and concepts according to their relative importance for defining energy literacy, also considering the use of language, terminology, and degree of specificity. The variety of opinions provided by the validity panel was particularly helpful for deliberating over the depth and breadth of scientific knowledge to be included (e.g., what school students may need to learn for state and national exams, vs. what types of information are vital to them as they become adults within the community). Ultimately, a set of characteristics was agreed upon that includes 40 concepts related to knowledge characteristics, six concepts related to attitude characteristics, and seven demonstrable behaviors related to the intention/behavior characteristics.

Taken as a whole, these characteristics and concepts that describe an energy-literate individual form a conceptual framework. The conceptual framework is a method for organizing the content of energy literacy in terms of fairly specific criteria, establishing the basis for the Instrument Development Framework.

\section{Results: The Instrument Development Framework}

The Instrument Development Framework is a natural extension of the conceptual framework, organized into an outline of content to be included in the literacy assessment instrument. ${ }^{30,31}$ The outline is strictly intended for instrument design, rather than as a basis for curriculum development. As such, it contains a comprehensive list of components that validate the construct of the assessment, broadly identifying topics rather than specifically indicating the required depth of mastery at any particular grade level.

A portion of the Instrument Development Framework is included in Table 1. The Cognitive Outcomes (knowledge) include topics that address an understanding of basic scientific concepts such as the laws of thermodynamics (conservation of energy; efficiency of energy conversion) and definitions and units of energy and power, but the majority of topics are more strongly tied to practical knowledge with respect to energy, such as issues related energy development and 
Table 1. Instrument Development Framework (an excerpt)

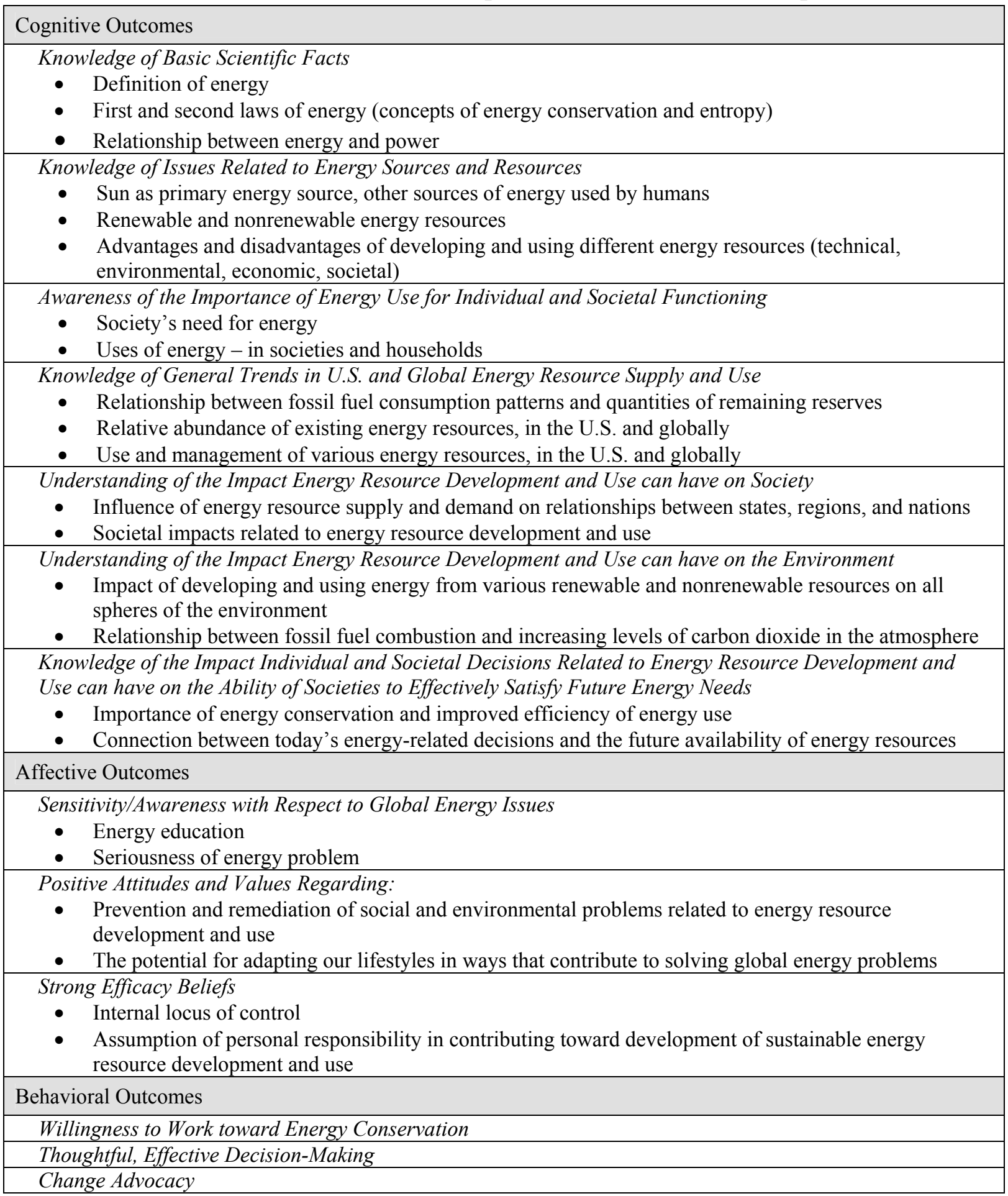

use, inequitable global energy supply and demand, nonrenewable energy resource depletion, and the environmental impacts associated with energy resource development and use. Affective Outcomes (attitude) include topics that are less specific and are intended to measure students' 
feelings about the urgency of our energy problem, their desire to learn and do more about energy conservation, and their belief in the relevance of their own decisions and actions to the overall global energy situation. Finally, the Behavioral Outcomes include a handful of opportunities for demonstrating intentions and behaviors that propose to gauge students' willingness to conserve energy with their everyday behaviors as well as their general capabilities for objective, critical evaluation of new ideas.

\section{In Conclusion: Moving toward the Final Instrument}

The Instrument Development Framework for energy literacy serves as the guidepost for developing the actual survey instrument. The framework forms the basis for selecting items, or questions, used in a pilot version of the Energy Literacy Scale. A pool of potential survey items, adapted from existing consumer- and student-oriented surveys related to energy and the environment, provides the starting point. The questions are all appropriate for the middle school age group, and use a combination of response formats including multiple choice, true/false, and Likert-scale. The selected items cover a broad range of topics within the energy arena, each primarily addressing one of the three themes within the framework - conveniently dividing the instrument into three corresponding subscales.

With the help of the validity panel, a set of survey items will be selected from the item pool for use in the pilot survey. Panel members evaluate each potential question in terms of five criteria: content validity, readability, accuracy, appropriateness of distracters, and age appropriateness of the question. This item-by-item evaluation provides the key for selecting 60 items to include in the pilot instrument that comprehensively addresses each of the identified concepts in the Framework.

The pilot survey will be administered to a variety of middle school students from various geographical locations and school types (urban vs. rural), who have had a wide range of exposure to energy-related topics. Middle school science and technology teachers will be recruited through a variety of mechanisms, using existing contacts through science and technology outreach programs, energy education networks, and web-based list serves of science and technology teachers throughout New York State. The total number of students involved in the pilot is anticipated to be on the order of 300-400.

Results from the pilot survey will be statistically analyzed to determine response frequencies, summary statistics, and reliability coefficients within each of the four subscales. A statisticallybased item analysis, in combination with a qualitative evaluation of the significance and relevance of each test item, will provide the basis for selecting 40 items most appropriate to include in the final instrument. A properly developed pilot instrument, combined with adequate test administration and thorough evaluation of results, will help ensure that the final instrument is a valid, reliable test of energy literacy.

A broad, efficient measure of energy literacy for middle and high school students encompassing both cognitive and affective outcomes - may prove useful in determining both baseline levels of literacy among groups of students as well to assess the effectiveness of energy education programs for improving energy literacy. Such assessment would provide valuable 
program feedback, enabling greater strides toward better educational programs and improved energy literacy.

\section{Acknowledgements}

This research was supported by the National Science Foundation through their Distinguished Teaching Scholar award (DUE-0428127).

\section{Bibliography}

1. KEEP, K-12 Energy Education Program: A Conceptual Guide to K-12 Energy Education in Wisconsin. Wisconsin K-12 Energy Education Program and the Wisconsin Center for Environmental Education, a publication of the Energy Center of Wisconsin: University of Stevens Point, Stevens Point, Wisconsin, 2003.

2. Barrow, L. H.; Morrisey, J. T., Ninth-Grade Students' Attitudes toward Energy: A Comparison between Maine and New Brunswick. Journal of Environmental Education 1987, 18, 15-21.

3. Gambro, J. S.; Switzky, H. N., Variables Associated with American High School Students' Knowledge of Environmental Issues Related to Energy and Pollution. Journal of Environmental Education 1999, 30, (2), 1522.

4. Hanson, R., Long-Term Effects of the Energy Source Education Program. Studies in educational evaluation : SEE 1993, 19, (4), 363.

5. NAEP (National Association of Educational Progress), Energy knowledge and attitudes: a national assessment of energy awareness among young adults. Education Commission of the States: Denver, Colorado, 1978.

6. NEETF, Americans' Low "Energy IQ:" A Risk to Our Energy Future/Why America Needs a Refresher Course on Energy. In National Environmental Education \& Training Foundation: Washington, DC, 2002.

7. NOWCAST, U.S. Public in the Dark on Climate Change Issues. American Meterological Society 2005, June 2005,775 .

8. Riecken, G.; Yavas, U., Energy Conservation Awareness. Ball State Business Review 1979, 9, (2), 2.

9. Ritchie, C. A.; Steinbrink, J. E., Knowledge, Attitude, and the Energy Ethic. Social Education 1984, 48, (2), $149-52$.

10. Barrow, L. H.; Morrisey, J. T., Energy Literacy of Ninth-Grade Students: A Comparison Between Maine and New Brunswick. Journal of Environmental Education 1989, 20, $22-25$.

11. Farhar, B. C., Energy and the Environment: the public view. Renewable Energy Report 1996, Issue Brief No. 3, $1-11$.

12. Pearson, G.; Young, A. T., Technically Speaking: Why all Americans need to know more about technology. National Academy Press: Washington, DC, 2002.

13. ISTE, National Educational Technology Standards, http://cnets.iste.org/students/s stands.html. (1/3/2007).

14. ITEA, Standards for technological literacy: Content for the study of technology. International Technology Education Association: Reston, VA, 2000. 
15. UNESCO, The Tbilisi Declaration, Intergovernmental Conference on Environmental Education: October 1426, 1977. In Essential Readings in Environmental Education, 2nd Edition, Hungerford, H.; Bluhm, W. J.; Volk, T. L.; Ramsey, J. M., Eds. Stipes Publishing, L.L.C.: Champaign, Illinois, 1977; pp 13-16.

16. UNESCO, Educating for a Sustainable Future: A transdisciplinary vision for concerted action. A report from the International Conference on Environment and Society: Education and Public Awareness for Sustainability. In Thessalokike, 8-12 December, 1997.

17. Disinger, J. F.; Roth, C. E., Environmental Literacy. ERIC/CSMEE Digest 1992, ED351201, 1-7.

18. Roth, C. E., Environmental Literacy: Its roots, evolution, and directions in the 1990s In Columbus, OH, ERIC/SMEAC Information Reference Center, 1992.

19. Roth, C. E., Benchmarks on the Way to Environmental Literacy K-12. In Developed by the Benchmarks for Environmental Literacy Project of the Massachusetts Secretaries Advisory Group of Environmental Education: 1996; Vol. ED392635.

20. Salmon, J., Are we building environmental literacy? Journal of Environmental Education 2000, 31, (4), 4-10.

21. St. Clair, R., Words for the World: Creating Critical Environmental Literacy for Adults. New Directions for Adult Continuing Education 2003, (99), 69-78.

22. Wilke, R., Environmental literacy and the college curriculum. EPA Journal 1995, 21, (2), 28.

23. Hofman, H., Energy Crisis - Schools to the rescue again. School Science and Mathematics 1980, 80, 468-478.

24. Solomon, J., Getting to know about energy: in school and society. Washington, D.C.: London, 1992; p xi, 201 p.

25. Stern, P. C., Toward a Coherent Theory of Environmentally Significant Behavior. Journal of Social Issues 2000, 56, (3), 407-424.

26. NEED (National Energy Education Development Project), Secondary Energy Poll, Page 39-41, Blueprint for Success. In The NEED Project: Manassas, VA (http://www.need.org/needpdf/SecondaryPoll.pdf), 2006.

27. Rendl, N. K., The Infusion and Evaluation of KEEP (K-12 Energy Education Program) as a Middle School Science Curriculum Resource inn Seventh Grade at John Muir Middle School, Unpublished Masters Thesis. University of Wisconsin, Stevens Point, WI, 2000.

28. Koballa, T. R., Changing attitudes toward energy conservation: the effect of development advancement on the salience of one-sided and two-sided persuasive communications. Journal of Research in Science Teaching 1984, 21, (6), 659-668.

29. Gay, L. R.; Mills, G. E.; Airasian, P., Educational Research: Competencies for Analysis and Applications. Pearson Merrill Prentice Hall: Upper Saddle River, NJ, 2006.

30. Peri, P., The Development of an Instrument to Assess Environmental Literacy of Eleventh Grade Students in Wisconsin. Unpublished Masters Thesis. University of Wisconsin, Stevens Point, WI, 1996.

31. Quale, A. M., The Development of an Instrument to Assess the Environmental Literacy of Fifth Grade Students in Wisconsin. Unpublished Masters Thesis. University of Wisconsin, Stevens Point, WI, 1993.

32. Kane, S. H., The Development, Evaluation, and Application of a Conceptual Framework for K-12 Renewable Energy Education. Unpublished Masters Thesis. University of Wisconsin, Stevens Point, WI, 2003. 
33. Champagne, A. B.; Klopfer, L. E., Criteria for Effective Energy Education; LRDC-1977/18; Pittsburgh Univ., PA. Learning Research and Development Center: Pittsburgh, PA, 1977; p 89.

34. National Research Council, National Science Education Standards. In National Research Council, National Academic Press. (httm://standards.nctm.org/): Washington, DC, 1996.

35. New York State Department of Education, Learning Standards for Mathematics, Science and Technology. New York State Department of Education: Albany NY. (http://www.emsc.nysed.gov/ciai/mst/pub/mststa1\&2.pdf), 1996. 